\title{
Towards simple and efficient molecular reporters: combining electron transfer and charge transfer in functional dyes of donor- acceptor-spacer-donor constitution
}

\author{
Knut Rurack $^{a, *}$ and Julia L. Bricks ${ }^{b}$ \\ ${ }^{a}$ Dept. I.3902, Federal Institute for Materials Research and Testing (BAM), Richard- \\ Willstaetter-Str. 11, D-12489 Berlin, Germany, ${ }^{\mathrm{b}}$ Institute of Organic Chemistry, National \\ Academy of Sciences, Murmanskaya Str. 5, 02094 Kiev-94, Ukraine \\ E-mail: knut.rurack@bam.de
}

(received 29 Mar 01; accepted 19 Sep 01; published on the web 27 Sep 01)

\begin{abstract}
Two 1-phenyl-3-R-5-(4-dimethylaminophenyl)- $\Delta^{2}$-pyrazolines which are functionalized with the heterocyclic acceptors $\mathrm{R}=$ pyridin-2-yl and quinolin-2-yl have been studied as simple and efficient molecular reporters that can be used for multimodal signaling of two different chemical analytes. As revealed by solvatochromic studies including a reference compound $(\mathrm{R}=4$ chlorophenyl), for derivatives with electron accepting 3-R-substituents in highly polar solvents, the strongly emissive charge-transfer (CT) state of the basic 1-phenyl-3-R- $\Delta^{2}$-pyrazoline chromophore is (partly) quenched by a fast intramolecular electron transfer (ET) from the electron-rich but electronically decoupled 5-receptor. In the case of the 3-pyridin-2-yl and 3quinolin-2-yl derivatives, this donor-acceptor-spacer-donor constitution allows to address the analyte-sensitive CT and ET processes separately by two different chemical stimuli. Metal ion binding to the 3-acceptor position and/or protonation of 3-acceptor and 5-donor lead to various changes of spectral band positions or band intensities, offering a variety of possible detection modes by the choice of absorption, excitation, and emission wavelenghts.
\end{abstract}

Keywords : Donor-acceptor-systems, heterocycles, electron transfer, fluorescence, chelates

\section{Introduction}

In chemistry and biology, analyte recognition, the determination of local environmental properties or the operation of molecular-scale switches require the efficient transduction of the actual event into a measurable signal, which is then detected by employing sensitive experimental techniques such as fluorometry. ${ }^{1,2}$ In the past few years, the optimization or tailormaking of the molecules that are at the heart of these monitoring or signaling processes have 
received a lot of attention. ${ }^{3-6}$ Besides improvements in sensitivity and selectivity, much research was focused on the design of advanced functional dyes that respond to two chemical stimuli ${ }^{7,8}$ or that can be operated in two different but independent transduction modes. ${ }^{9}$ Aiming at a simultaneous and/or cooperative recognition of two different chemical species, the combination of two individually addressable and electronically largely decoupled receptors presents a promising design rationale. Furthermore, if one binding unit is an integral part of the chromophore and the other receptor is located at a remote (decoupled) site, cooperative photophysical effects can easily be achieved. For instance, such bimodal signaling processes can be invoked by using a donor-acceptor- (D-A) substituted chromophore that shows intramolecular charge transfer (CT) absorption and fluorescence bands, and a second receptor with an electronic configuration that can quench the emission of the fluorophore via a long-range excited-state process such as electron transfer (ET). For such molecular systems, analyte-binding in the chromophore-localized receptor directly affects donor or acceptor strength of the charge transfer processing moiety and engagement of the second coordination site can arrest the ET. Consequently, the first event commonly leads to spectral shifts and the second to a revival of the quenched fluorescence. A simple constitution that allows to construct individually configurable bifunctional molecular reporters is the donor-acceptor-spacer-donor arrangement of 1,3,5triaryl- $\Delta^{2}$-pyrazolines. ${ }^{10}$ Despite being structurally the center of these dyes, the only partly unsaturated five-membered ring has a central position as it (i) is part of the basic chromophore, (ii) contains a nitrogen donor atom which is a potential coordination site for a metal ion, ${ }^{11}$ and (iii) holds the 5-substituent in a non-conjugated, fixed and pseudo-spiro-oriented configuration, i.e. in a rather closely neighbored yet electronically decoupled position. ${ }^{12}$ Here, we present the two bifunctional 1,3,5-triaryl- $\Delta^{2}$-pyrazolines 1 and $\mathbf{2}$ which are capable of signaling aminophilic metal ions (e.g. $\mathrm{Hg}^{2+}$ ) and protons with various transduction modes.

\section{Results and Discussion}

The modular construction principle of the 1,3,5-triaryl- $\Delta^{2}$-pyrazolines is depicted in Scheme 1 . The potentially electron donating receptor in the 5-position is introduced via a functionalized benzaldehyde (4) and the acceptor part of the intermediate chalcone 6 contains at least one of the donor atoms of the receptor fragment of the chromophore, the heterocyclic nitrogen atom. The basic bidentally chelating structure of this CT-active binding site and the fixation of the 1-, 3and 5 -substituents is achieved by reaction of 6 with phenylhydrazine to yield the 1,3,5-triaryl- $\Delta^{2}$ pyrazoline with its characteristic rigid and partly unsaturated five-membered ring. 


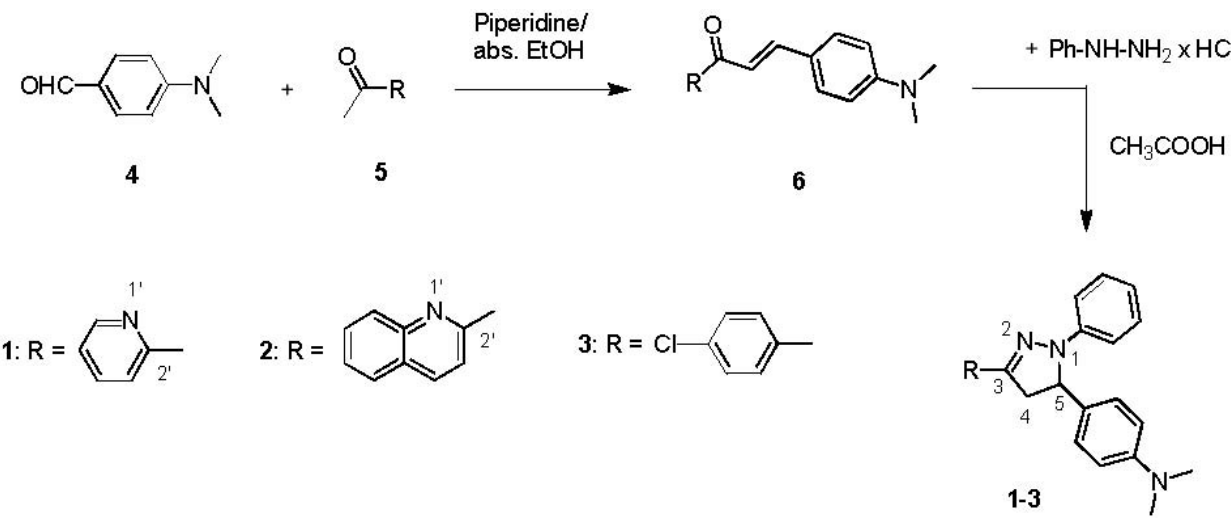

\section{Scheme 1}

\section{Solvent-dependent spectroscopic behavior in the absence of chemical stimuli}

In accordance with results obtained on related 3-benzothiazol-2-yl-substituted triaryl- $\Delta^{2}$ pyrazolines, ${ }^{10} \mathbf{1}, 2$ and the reference compound 3 which lacks a potential binding site in its 1,3chromophoric part show rather unstructured, broad and largely Stokes-shifted absorption and emission bands in apolar as well as polar solvents. As an example, the spectra of 2 in acetonitrile and diethylether are given in Figure 1.

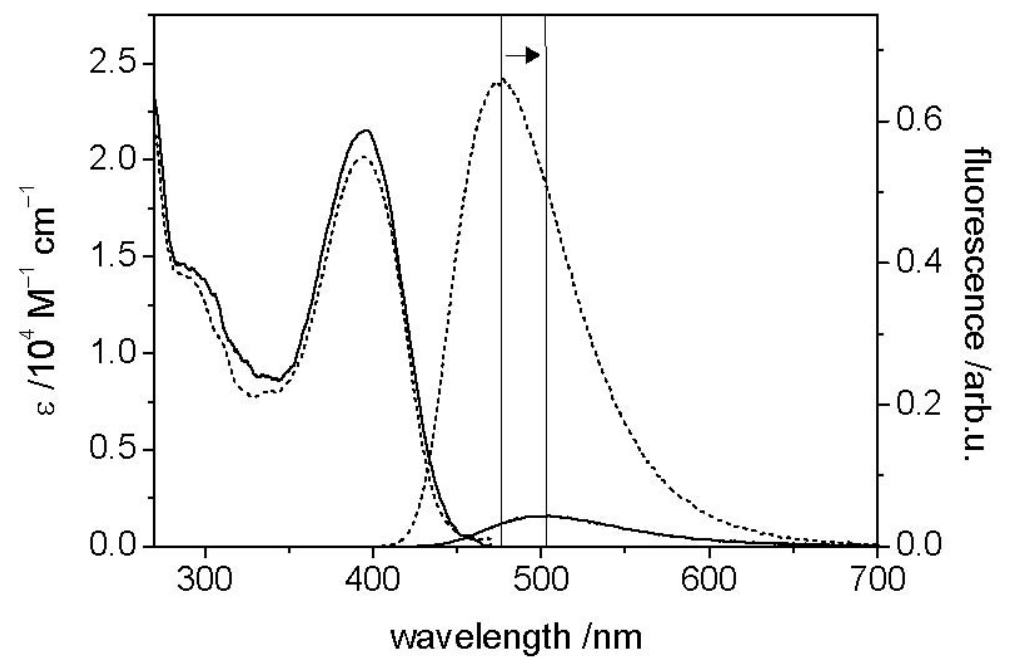

Figure 1. Absorption and emission spectra of 2 in acetonitrile $(-)$ and diethylether $(---)$, the arrow indicating the shift of the emission band maximum upon going from $\mathrm{Et}_{2} \mathrm{O}$ to $\mathrm{MeCN}$.

The negligible shifts in absorption upon increasing the polarity of the solvent suggest that the ground state dipole moments are comparatively small. For instance, absorption maxima of 394 and $395 \mathrm{~nm}$ are obtained for 2 in acetonitrile and diethylether (Figure 1) and a ground-state dipole moment of $\mu_{\mathrm{g}}(2)=1.0 \mathrm{D}^{13}$ is theoretically determined on the basis of the AM1optimized $^{14}$ ground-state geometry. In contrast, the increasing Stokes shift with increasing solvent polarity indicates a higher dipole moment of the emissive species, formed by an excited- 
state charge transfer from the phenyl-N(1) fragment to the 3 -acceptor. ${ }^{10}$ As follows from Table 1 which combines the spectroscopic data of 1-3 in two solvents of different polarity, the fluorescence of 1-3 is characterized by high quantum yields in apolar and medium polar solvents, e.g. $\Phi_{\mathrm{f}}=0.78$ for $\mathbf{1}, 0.66$ for 2 , and 0.76 for 3 in diethylether.

In acetonitrile, however, $1\left(\Phi_{\mathrm{f}}=0.30\right)$ and especially $2\left(\Phi_{\mathrm{f}}=0.01\right)$ show quenched emission as compared to $3\left(\Phi_{\mathrm{f}}=0.68\right)$. Such a correlation of 3-acceptor strength and emission behavior as manifested in red-shifted fluorescence band position and reduced quantum yield in highly polar solvents has also been found in a comparative study of 3-benzothiazol-2-yl- and 3-phenylsubstituted triaryl- $\Delta^{2}$-pyrazolines and was ascribed to a competition of radiative deactivation of the $\mathrm{S}_{1}$ state (via an allowed $\mathrm{S}_{0} \leftarrow{ }^{1} \mathrm{CT}$ transition) and electron transfer (ET) quenching from the electronically decoupled, remote and electron-rich 5-(4-dimethylaminophenyl) substituent. ${ }^{10}$ Due to the $\mathrm{sp}^{3}$-hybridization of $\mathrm{C}(5)$ and the rigidity of the central five-membered ring the 5substituent is held in a pseudo-spiro orientation, this donor-acceptor-spacer-donor constitution preventing pronounced electronic interaction of both molecular subunits in the ground state. ${ }^{10}$ Only in the excited state, a long-range process such as ET can take place. Analysis of the fluorescence lifetime data revealed that the reduced fluorescence quantum yields are accompanied by shorter fluorescence decay times thus indicating increased rate constants of nonradiative deactivation $k_{\mathrm{nr}}$ and virtually unchanged rate constants of fluorescence $k_{\mathrm{f}}$. For instance, whereas $k_{\mathrm{nr}}=\left(1-\Phi_{\mathrm{f}}\right) / \tau_{\mathrm{f}}$ of 2 was determined to $198 \times 10^{8} \mathrm{~s}^{-1}$ and $1 \times 10^{8} \mathrm{~s}^{-1}$ in acetonitrile and diethylether, $k_{\mathrm{f}}(2)=\Phi_{\mathrm{f}} / \tau_{\mathrm{f}}$ was found to be very similar in both solvents with ca. $2 \times 10^{8} \mathrm{~s}^{-1}$ (for the spectroscopic data, see Table 1).

Table 1. Spectroscopic data of 1-3 in acetonitrile and diethyl ether

\begin{tabular}{ccccccc}
\hline & Solvent & $\begin{array}{c}\lambda(\mathrm{abs}) \\
{[\mathrm{nm}]}\end{array}$ & $\begin{array}{c}\lambda(\mathrm{em}) \\
{[\mathrm{nm}]}\end{array}$ & $\begin{array}{c}\text { Stokes shift } \\
{\left[\mathrm{cm}^{-1}\right]}\end{array}$ & $\Phi_{\mathrm{f}}$ & $\begin{array}{c}\tau_{\mathrm{f}} \\
{[\mathrm{ns}]}\end{array}$ \\
\hline $\mathbf{1}$ & $\mathrm{MeCN}$ & 370 & 477 & 6060 & 0.30 & 2.08 \\
$\mathbf{1}$ & $\mathrm{Et}_{2} \mathrm{O}$ & 370 & 455 & 5050 & 0.78 & 3.83 \\
$\mathbf{2}$ & $\mathrm{MeCN}$ & 394 & 502 & 5460 & 0.01 & 0.05 \\
$\mathbf{2}$ & $\mathrm{Et}_{2} \mathrm{O}$ & 395 & 476 & 4310 & 0.66 & 3.31 \\
$\mathbf{3}$ & $\mathrm{MeCN}$ & 368 & 469 & 5810 & 0.68 & 3.99 \\
$\mathbf{3}$ & $\mathrm{Et}_{2} \mathrm{O}$ & 369 & 449 & 4830 & 0.76 & 3.60 \\
\hline
\end{tabular}

The dependence of the quenching process on the careful choice of an appropriate 3-acceptor can be directly concluded from the data in Table 1 . Whereas the absorption bands of $\mathbf{1}$ and $\mathbf{3}$ are superimposed in acetonitrile and their emission bands are only shifted for ca. $10 \mathrm{~nm}$, the fluorescence of $\mathbf{1}$ is markedly reduced. Apparently, when designing such bifunctional dyes a substitutent with a Hammett constant $\sigma_{\mathrm{p}} \geq 0.17$ (value for 2-pyridyl; $\sigma_{\mathrm{p}}=0.12$ for 4chlorophenyl $^{15}$ is necessary to activate an ET from a 5-(4-dimethylaminophenyl) group in highly polar solvents as acetonitrile. 


\section{Signaling $\mathrm{Hg}^{2+}$ and $\mathrm{H}^{+}$with $\mathbf{1}$ and 2 in acetonitrile}

The potential of the 3-heterocycle-substituted 1,3,5-triaryl- $\Delta^{2}$-pyrazolines $\mathbf{1}$ and $\mathbf{2}$ to serve as fluorescent sensor molecules for the independent or simultaneous detection of protons and $\mathrm{Hg}^{2+}$ ions was studied in acetonitrile. In agreement with the charge transfer from the $\mathrm{Ph}-\mathrm{N}(1)$ to the $\mathrm{A}-\mathrm{C}(3)=\mathrm{N}(2)$ fragment, coordination of $\mathrm{Hg}^{2+}$ to the acceptor chelate $\mathrm{N}\left(1^{\prime}\right)-\mathrm{C}\left(2^{\prime}\right)-\mathrm{C}(3)=\mathrm{N}(2)$ (Scheme 2) drastically increases the acceptor strength and leads to a strong bathochromic shift in absorption (Table 2). The similar Stokes shifts of ca. $6100 \mathrm{~cm}^{-1}$ as well as $5100 \mathrm{~cm}^{-1}$ found for free $\mathbf{1}$ and $\mathrm{Hg}^{2+}-\mathbf{1}$ as well as free $\mathbf{2}$ and $\mathrm{Hg}^{2+}-\mathbf{2}$ stress the fact that such acceptor complexes are stable in the excited state ${ }^{16}$ and consequently, the emission of these species appears in the red visible region of the spectrum (Table 2; the notation $\mathrm{Hg}^{2+}-\mathbf{X}$ indicates binding to the 3 -acceptor, $\mathrm{X}-\mathrm{H}^{+}$binding to the 5-receptor, vide infra). However, based on the experimental and theoretical studies described in detail in ref. 10, this cation-induced increase of the acceptor strength does not only facilitate the charge transfer but also accelerates the ET process, leading to an overall strongly quenched emission.

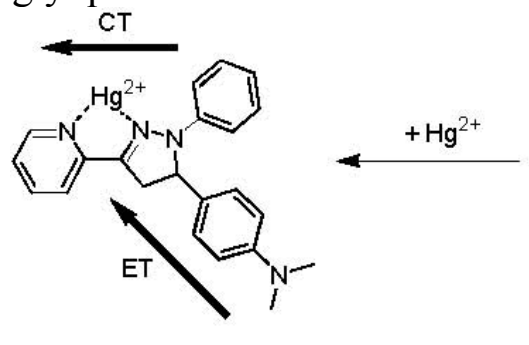

$\mathrm{Hg}^{2+}-1$

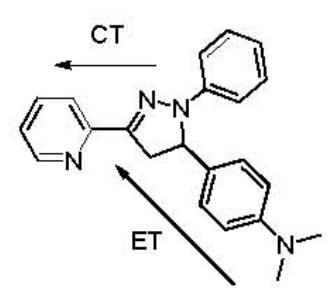

1

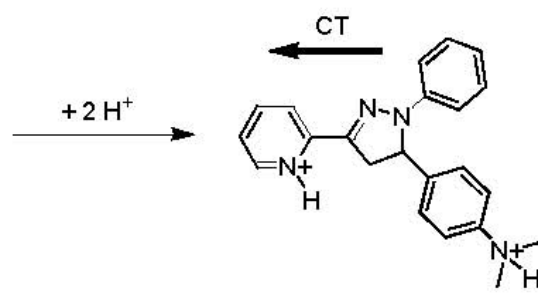

$\mathrm{H}^{+}-1-\mathrm{H}^{+}$

Scheme 2. Schematic representation of $\mathrm{Hg}^{2+}$ and $\mathrm{H}^{+}$signaling with $\mathbf{1}$ (bold arrows indicate increasing character of the intramolecular charge and electron transfer processes)

For protons, the situation is different. Due to the strong conjugation within the 1,3-diaryl- $\Delta^{2}-$ pyrazoline fragment the basicity of the heterocyclic nitrogen atom $\mathrm{N}\left(1^{\prime}\right)$ is comparatively high. Thus, in a titration of $\mathbf{1}$ and $\mathbf{2}$ with perchloric acid in acetonitrile protonation occurs almost simultaneously at the 4-dimethylaminophenyl group in the 5-position and at the 3-acceptor (Scheme 2), entailing a bathochromic shift of both absorption and emission bands while maintaining a moderate fluorescence (Table 2).

Table 2. Spectroscopic data of 1 and 2 in the presence of $\mathrm{Hg}^{2+}$ and $\mathrm{H}^{+}$in acetonitrile

\begin{tabular}{ccccc}
\hline & $\begin{array}{c}\lambda(\mathrm{abs}) \\
{[\mathrm{nm}]}\end{array}$ & $\begin{array}{c}\lambda(\mathrm{em}) \\
{[\mathrm{nm}]}\end{array}$ & $\begin{array}{c}\text { Stokes shift } \\
{\left[\mathrm{cm}^{-1}\right]}\end{array}$ & $\Phi_{\mathrm{f}}$ \\
\hline $\mathrm{Hg}^{2+}-\mathbf{1}$ & 438 & 605 & 6300 & $2 \times 10^{-3}$ \\
$\mathrm{H}^{+}-\mathbf{1}-\mathrm{H}^{+}$ & 449 & 616 & 6040 & 0.034 \\
$\mathrm{Hg}^{2+}-\mathbf{2}$ & 489 & 652 & 5110 & $5 \times 10^{-4}$ \\
$\mathrm{H}^{+}-\mathbf{2}-\mathrm{H}^{+}$ & 486 & 653 & 5260 & 0.014 \\
\hline
\end{tabular}


Besides ET quenching rates, this difference between $\mathrm{H}^{+}$and $\mathrm{Hg}^{2+}$ binding to the two receptor sites of 1 and 2 can be directly measured in absorption, i.e., the decrease of the anilino-localized absorption band at ca. $260 \mathrm{~nm}$ (Figure $2 \mathrm{~A} \rightarrow \mathrm{B}$ and $\mathrm{D} \rightarrow \mathrm{C}$ ). When the 5-receptor is protonated, this part of the composite chromophore is "switched off" and its band disappears in the spectrum. Interestingly, both $\mathrm{Hg}^{2+}-\mathbf{1}-\mathrm{H}^{+}\left(\Phi_{\mathrm{f}}=0.32\right)$ and $\mathrm{Hg}^{2+}-2-\mathrm{H}^{+}\left(\Phi_{\mathrm{f}}=0.013\right)$ show comparable fluorescence quantum yields as the doubly protonated species $\mathrm{H}^{+}-\mathbf{X}-\mathrm{H}^{+}$(see Table 2), suggesting that enhanced intersystem crossing as a consequence of binding to the "heavy ion"17 $\mathrm{Hg}^{2+}$ does not largely interfere. ${ }^{18}$ Since in the case of $\mathrm{Hg}^{2+}$ the effects were found at distinctly lower concentrations as compared to $\mathrm{H}^{+}$, this rather high fluorescence of $\mathrm{Hg}^{2+}-\mathbf{X}-\mathrm{H}^{+}$seems not to be due to an analyte exchange at the 3-acceptor binding site. Recently, we have observed a similar behavior for a related fluoroionophore with two $\mathrm{Hg}^{2+}$-responsive binding sites at the 3and 5-positions. ${ }^{10}$

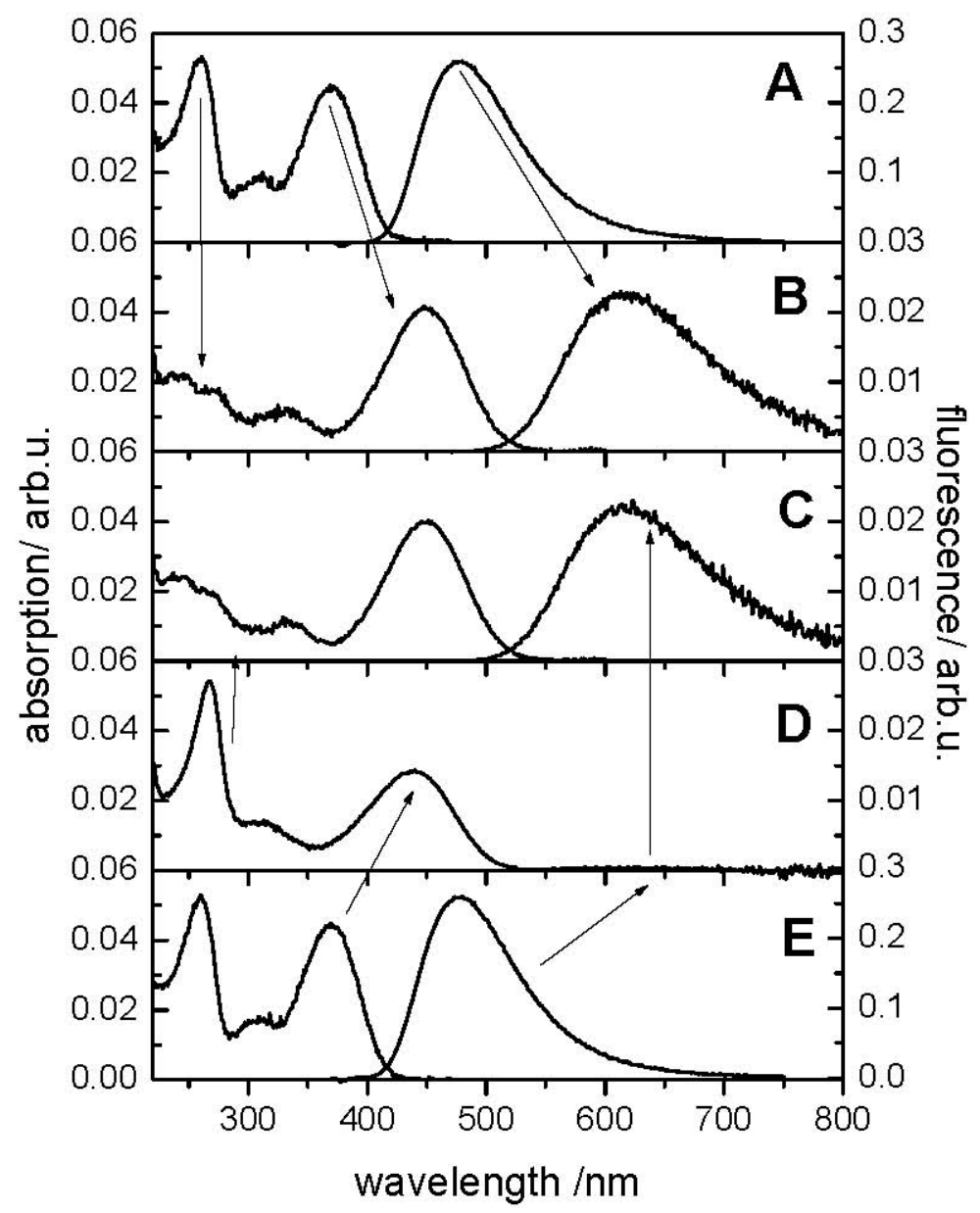

Figure 2. Absorption and emission spectra of 1 in the presence of $\mathrm{Hg}^{2+}$ and $\mathrm{H}^{+}$in acetonitrile (the arrows indicate the changes upon analyte addition; $\mathrm{c}_{1}=2 \times 10^{-6} \mathrm{M}, \mathrm{c}_{\mathrm{Hg}}=2 \times 10^{-6} \mathrm{M}, \mathrm{c}_{\mathrm{H}}=2$ $\left.\times 10^{-5} \mathrm{M}\right) . \mathrm{A} \rightarrow \mathrm{B}$ : addition of $\mathrm{H}^{+}$to 1 yields $\mathrm{H}^{+}-1-\mathrm{H}^{+} ; \mathrm{B} \rightarrow \mathrm{C}$ : addition of $\mathrm{Hg}^{2+}$ to this species has virtually no effect; $\mathrm{E} \rightarrow \mathrm{D}$ : addition of $\mathrm{Hg}^{2+}$ to $1 ; \mathrm{D} \rightarrow \mathrm{C}: \mathrm{Hg}^{2+}-1+\mathrm{H}+$ results in $\mathrm{Hg}^{2+}-1-\mathrm{H}$. 
The composite nature of the chromophore and the mechanisms outlined above are further supported by the results obtained for the reference compound 3 in the presence of $\mathrm{H}^{+}$and $\mathrm{Hg}^{2+}$. At low concentrations where $\mathbf{1}$ and $\mathbf{2}$ are fully complexed, $\mathrm{Hg}^{2+}$ does not affect the absorption or fluorescence properties of 3 . Only at a $>100$-fold excess, diffusion-controlled dynamic quenching of the emission of the dye is observed. Thus, acceptor chelate formation is essential for signaling $\mathrm{Hg}^{2+}$. Addition of $\mathrm{H}^{+}$at a concentration of $2 \times 10^{-5} \mathrm{M}$ leads to the disappearance of the $260 \mathrm{~nm}$ absorption band, indicating protonation of the 5-receptor. However, the other spectroscopic features of $\mathbf{3}$ are only subject to very minor changes, i.e. hypsochromic shifts of 3 $\mathrm{nm}$ are found for the 1,3-chromophore's absorption and emission bands. The fluorescence quantum yield of 3 in acetonitrile is not affected by the presence of $2 \times 10^{-5} \mathrm{M}$ protons.

Table 3. "Spectroscopic truth table" for 1 (and 2), $\mathrm{Hg}^{2+}$, and $\mathrm{H}^{+}$in acetonitrile

\begin{tabular}{cccccc}
\hline $\mathrm{H}^{+}$ & $\mathrm{Hg}^{2+}$ & $\begin{array}{l}\text { abs. 370 (400) nm } \\
\text { em. 475 (500) nm }\end{array}$ & abs. 440 (485) nm & em. 600(650) nm & abs. 270 nm \\
\hline 0 & 0 & 1 & 0 & 0 & 1 \\
0 & 1 & 0 & 1 & 0 & 1 \\
1 & 0 & 0 & 1 & 1 & 0 \\
1 & 1 & 0 & 1 & 1 & 0 \\
\hline
\end{tabular}

The future potential of such simple yet individually configurable molecular reporters in simultaneous or cooperative analyte signaling are obvious when certain absorption and fluorescence data are combined in a "spectroscopic truth table", Table 3. Here, "0" and "1" stand for the digital information concerning the presence or absence of a stimulus or signal. When monitoring the original absorption and emission bands of the free dyes, a high signal output is only found in the absence of both analytes, transducing a NOR event. ${ }^{19}$ The reverse case, an OR logic gate, is obtained when measuring the absorption at, e.g. 445 or $485 \mathrm{~nm}$ for 1 or 2 . Positioning the emission monochromator in the red fluorescence band, an intense signal is only recorded whenever protons are present, i.e. such a response identifies protons with an ID digital action. Finally, observing the absorption of the 5-receptor at ca. $260 \mathrm{~nm}$, the identification of protons is indirectly transduced by a so-called inverted (INV) event, i.e. this absorption band is also a function of only one particular variable. A combination of the diverse measurement modes can thus be exploited for cooperative or simultaneous signaling actions.

\section{Experimental Section}

Materials. $\mathrm{Hg}\left(\mathrm{ClO}_{4}\right)_{2}$ purchased from Aldrich was of highest purity available and dried in a vacuum oven before use. ${ }^{20}$ (Caution: Perchlorate salts present a potential explosion hazard and should be handled with care and possibly only in small quantities!) All the solvents employed 
were of UV spectroscopic grade (Aldrich, Merck).

General Procedures. NMR spectra were obtained with a $500 \mathrm{MHz}$ NMR spectrometer Varian Unity plus 500 in $\mathrm{CDCl}_{3}$ solution, with $\mathrm{CDCl}_{3}$ as internal standard. The melting points (mp) measured with a digital melting point analyzer IA 9100 (Kleinfeld $\mathrm{GmbH}$ ) are uncorrected.

General procedure for preparation of compounds 1-3. $0.21 \mathrm{~g}(1.5 \mathrm{mmol})$ phenylhydrazine hydrochloride and the corresponding chalcone ${ }^{21-23}(1 \mathrm{mmol})$ were heated for $3 \mathrm{~h}$ at $100{ }^{\circ} \mathrm{C}$ in a solution of $5 \mathrm{~mL}$ absolute ethanol and $0.5 \mathrm{ml}$ acetic acid. The resulting reaction mixture was poured into $50 \mathrm{~mL}$ ice water and neutralized with $10 \%$ aqueous sodium carbonate. The solid precipitate was separated and washed with water and the product was purified by column chromatography (silica, cyclohexane/chloroform 2:1). After evaporation of the solvent, the 1,3,5triaryl- $\Delta^{2}$-pyrazolines were recrystallized from hexane 1, i-propanol 2 or acetonitrile 3.

1-Phenyl-3-pyridin-2-yl-5-[4-( $N, N$-dimethylamino)-phenyl]- $\Delta^{2}$-pyrazoline (1). Yield: $23 \%$; yellow prisms; m.p. $155-157{ }^{\circ} \mathrm{C}$; ${ }^{1} \mathrm{H}$ NMR $\delta: 2.90\left(\mathrm{~s}, 6 \mathrm{H}, \mathrm{CH}_{3}\right), 3.25-3.34\left(\mathrm{dd}, 1 \mathrm{H}, \mathrm{CH}_{2} \mathrm{C}=\mathrm{N}\right)$, 3.86-3.96 (dd, $\left.1 \mathrm{H}, \mathrm{CH}_{2} \mathrm{C}=\mathrm{N}\right), 5.23-5.30(\mathrm{dd}, 1 \mathrm{H}, \mathrm{ArCHN}), 6.65-6.68(\mathrm{~d}, 2 \mathrm{H}$, arom. H), 6.69$6.81(\mathrm{t}, 1 \mathrm{H}$, arom. H), 7.11-7.21 (m, 7H, arom. H), 7.63-7.69 (td, 1H arom. H), 8.10-8.13 (d, $1 \mathrm{H}$, arom. H), 8.51-8.53 (dd, $1 \mathrm{H}$, arom. $\mathrm{H}) ;{ }^{13} \mathrm{C} \mathrm{NMR} \delta: 40.56\left(\mathrm{CH}_{3} \mathrm{~N}\right), 43.12\left(\mathrm{CH}_{2}\right), 64.31$ $(\mathrm{ArCHN}), 112.95,113.62,119.32,120.55,122.44,126.68,126.86,130.03,135.84,144.47$, 147.95, 149.06, 149.88, 152.35 (arom. C). Anal. Calcd. for $\mathrm{C}_{22} \mathrm{H}_{22} \mathrm{~N}_{4}: \mathrm{C}, 77.16 ; \mathrm{H}, 6.48 ; \mathrm{N}$, 16.36. Found: C, 77.22; H, 6.30; N, 16.33.

1-Phenyl-3-quinolin-2-yl-5-[4-( $N, N$-dimethylamino)-phenyl]- $\Delta^{2}$-pyrazoline (2). Yield: $33 \%$; yellow powder; m.p. $182-184{ }^{\circ} \mathrm{C} ;{ }^{1} \mathrm{H}$ NMR $\delta: 2.91\left(\mathrm{~s}, 6 \mathrm{H}, \mathrm{CH}_{3}\right), 3.40-3.52\left(\mathrm{dd}, 1 \mathrm{H}, \mathrm{CH}_{2} \mathrm{C}=\mathrm{N}\right)$, 3.96-4.10 (dd, 1H, $\left.\mathrm{CH}_{2} \mathrm{C}=\mathrm{N}\right), 5.28-5.40(\mathrm{dd}, 1 \mathrm{H}, \mathrm{ArCHN}), 6.66-6.68(\mathrm{~d}, 2 \mathrm{H}$, arom. H), 6.76$6.90\left(\mathrm{~m}, 1 \mathrm{H}\right.$, arom. H), 7.16-8.31 (m, 12H, arom.H); ${ }^{13} \mathrm{C} \mathrm{NMR} \delta: 40.54\left(\mathrm{CH}_{3} \mathrm{~N}\right), 42.96\left(\mathrm{CH}_{2}\right)$, 64.56 (ArCHN), 112.97, 113.76, 118.88, 119.54, 125.50, 126.24, 127.51, 127.57, 128.92, 129.39, 135.31, 136.06, 144.27, 148.07, 148.73, 149.99, 152.53 (arom.C). Anal. Calcd. for $\mathrm{C}_{26} \mathrm{H}_{24} \mathrm{~N}_{4}$ : C, 79.56; H, 6.16; N, 14.27. Found: C, 79.44; H, 6.05; N, 14.40.

1-Phenyl-3-(4-chlorophenyl)-5-[4-( $N, N$-dimethylamino)-phenyl]- $\Delta^{2}$-pyrazoline (3). Yield 78\%; yellow needles; m.p. 162-164 ${ }^{\circ} \mathrm{C} ;{ }^{1} \mathrm{H}$ NMR $\delta: 2.91\left(\mathrm{~s}, 6 \mathrm{H}, \mathrm{NCH}_{3}\right), 3.02-3.10(\mathrm{dd}, 1 \mathrm{H}$, $\left.\mathrm{CH}_{2} \mathrm{C}=\mathrm{N}\right), 3.67-3.77\left(\mathrm{dd}, 1 \mathrm{H}, \mathrm{CH}_{2} \mathrm{C}=\mathrm{N}\right), 5.16-5.22(\mathrm{dd}, 1 \mathrm{H}, \operatorname{ArCHN}), 6.68-6.79$ (m, 3H, arom. $\mathrm{H}), 7.07-7.19$ (m, 6H, arom. $\mathrm{rH}), 7.31-7.37$ (d, 2H, arom. H), 7.60-7.63 (d, 2H, arom. H); ${ }^{13} \mathrm{C}$

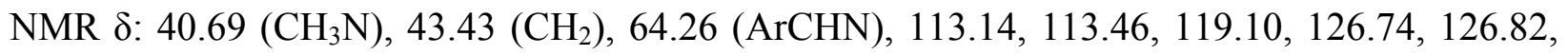
128.69, 128.86, 131.53, 134.04, 144.78, 145.53 (arom. C). Anal. Calcd. for $\mathrm{C}_{23} \mathrm{H}_{21} \mathrm{ClN}_{3}$ : C, 73.69; H, 5.65; N, 11.21. Found: C, 73.60; H, 5.53; N, 11.10 .

Absorption and fluorescence spectroscopy. UV/Vis absorption and steady-state emission spectra were recorded on a Carl Zeiss Specord M400/M500 absorption spectrometer and a Spectronics Instruments 8100 spectrofluorometer at room temperature. For the determination of the relative fluorescence quantum yields $\left(\Phi_{\mathrm{f}}\right)$, coumarin 1 in ethanol $\left(\Phi_{\mathrm{f}}=0.5\right),{ }^{24}$ coumarin 153 in ethanol $\left(\Phi_{\mathrm{f}}=0.4\right),{ }^{24}$ and DCM in methanol $\left(\Phi_{\mathrm{f}}=0.43\right)^{25}$ were used as fluorescence standards 
and the uncertainties of the measurement were determined to $\pm 5 \%$ (for $\Phi_{\mathrm{f}}>0.2$ ), $\pm 10 \%$ (for $0.2>\Phi_{\mathrm{f}}>0.02$ ), $\pm 20 \%$ (for $0.02>\Phi_{\mathrm{f}}>5 \times 10-3$ ), and $\pm 30 \%$ (for $5 \times 10-3>\Phi_{\mathrm{f}}$ ), respectively. Fluorescence lifetimes $\left(\tau_{\mathrm{f}}\right)$ were measured employing a unique laser impulse fluorometer with picosecond time resolution described elsewhere. ${ }^{26}$ The fluorescence decays were recorded with a time division of $5.2 \mathrm{ps} \mathrm{channel}^{-1}$ and details on detection, calibration and fitting procedures are given in ref. 10.

\section{Acknowledgements}

Financial support by the Deutsche Forschungsgemeinschaft and BAM-MOE is gratefully acknowledged.

\section{References and Notes}

1. Topics in Fluorescence Spectroscopy, Lakowicz, J. R., Ed.; Vol. 1-4; Plenum: New York, 1994.

2. Applied Fluorescence in Chemistry, Biology, and Medicine; Rettig, W., Strehmel, B., Schrader, S., Seifert, H., Eds.; Springer: Berlin, 1999.

3. de Silva, A. P.; Gunaratne, H. Q. N.; Gunnlaugsson, T.; Huxley, A. J. M.; McCoy, C. P.; Rademacher, J. T.; Rice, T. E. Chem. Rev. 1997, 97, 1515.

4. Valeur, B.; Leray, I. Coord. Chem. Rev. 2000, 205, 3.

5. Wosnick, J. H.; Swager, T. M. Curr. Opin. Chem. Biol. 2000, 4, 715.

6. Beer, P. D.; Gale, P. A. Angew. Chem. Int. Ed. 2001, 40, 486.

7. de Silva, A. P.; McClenaghan, N. J. Am. Chem. Soc. 2000, 122, 3965.

8. McSkimming, G.; Tucker, J. H. R.; Bouas-Laurent, H.; Desvergne, J.-P. Angew. Chem. Int. Ed. 2000, 39, 2167.

9. Rurack, K.; Kollmannsberger, M.; Daub, J. Angew. Chem. Int. Ed. 2001, 40, 385.

10. Rurack, K.; Bricks, J. L.; Schulz, B.; Maus, M.; Reck, G.; Resch-Genger, U. J. Phys. Chem. A 2000, 104, 6171.

11. de Silva, A. P.; Dixon, I. M.; Gunaratne, H. Q. N.; Gunnlaugsson, T.; Maxwell, P. R. S.; Rice, T. E. J. Am. Chem. Soc. 1999, 121, 1393.

12. Rurack, K.; Resch-Genger, U.; Bricks, J. L.; Spieles, M. Chem. Commun. 2000, 2103.

13. For the energetically more stable anti isomer (with respect to $\mathrm{N}(2)$ and $\mathrm{N}\left(1^{\prime}\right)$ ) of $2 ; \mu_{\mathrm{g}}=1.0$ $\mathrm{D}$ for the anti isomer of $\mathbf{1}$ and 1.9 D for 3.

14. Dewar, M. J. S.; Zoeblich, E. G.; Healy, E. F.; Stewart, J. P. P. J. Am. Chem. Soc. 1985, 107, 3202. (Ampac V5.0 and V6.55, Semichem, Inc.)

15. Hansch, C.; Leo, A.; Taft, R. W. Chem. Rev. 1991, 91, 165.

16. Rettig, W.; Rurack, K.; Sczepan, M. In New Trends in Fluorescence Spectroscopy: 
Applications to Chemical and Life Sciences; Valeur, B., Brochon, J. C., Eds.; Springer: Berlin, 2001; pp. 125-155.

17. In terms of the heavy atom effect, see Masuhara, H.; Shioyama, H.; Saito, T.; Hamada, K.; Yasoshima, S.; Mataga, N. J. Phys. Chem. 1984, 88, 5868.

18. Note that the order of addition of the chemical triggers makes no difference with respect to the resulting spectra and fluorescence intensities, i.e. $\mathbf{X}+\mathrm{H}^{+}+\mathrm{Hg}^{2+}$ and $\mathbf{X}+\mathrm{Hg}^{2+}+\mathrm{H}^{+}$both yield similar species of $\mathrm{Hg}^{2+}-\mathbf{X}-\mathrm{H}^{+}$-type.

19. Burger, P. Digital Design, A Practical Course; J. Wiley \& Sons: New York, 1988.

20. Gmelins Handbuch der Anorganischen Chemie. Chlor; $8^{\text {th }}$ Edn; VCH: Berlin, 1927.

21. Annigeri, A. C.; Siddappa, S. Indian J. Chem. 1963, 1, 484.

22. Zukerman, S. V.; Shon, C. K.; Lavrushin, V. F. Zh. Org. Khim. 1964, 34, 2881.

23. Rurack, K.; Dekhtyar, M. L.; Bricks, J. L.; Resch-Genger, U.; Rettig, W. J. Phys. Chem. A 1999, 103, 9626.

24. Drexhage, K. H. J. Res. Natl. Bur. Stand. 1976, 80A, 421.

25. Drake, J. M.; Lesiecki, M. L.; Camaioni, D. M. Chem. Phys. Lett. 1985, 113, 530.

26. Resch, U.; Rurack, K. Proc. SPIE-Int. Soc. Opt. Eng. 1997, 3105, 96. 